\title{
Erratum to: Genomic and functional features of the biosurfactant producing Bacillus sp. AM13
}

\author{
Shraddha Shaligram ${ }^{1,2}$ • Shreyas V. Kumbhare ${ }^{2}$ - Dhiraj P. Dhotre ${ }^{2}$. \\ Manohar G. Muddeshwar' ${ }^{1}$ Atya Kapley ${ }^{3}$ - Neetha Joseph ${ }^{2}$ - Hemant J. Purohit ${ }^{3}$. \\ Yogesh S. Shouche ${ }^{2} \cdot$ Shrikant P. Pawar ${ }^{2}$
}

Published online: 25 November 2016

(C) Springer-Verlag Berlin Heidelberg 2016

Erratum to: Funct Integr Genomics (2016) 16:557-566

DOI 10.1007/s10142-016-0506-z

The original version of this article unfortunately contained a mistake. One of the authors middle initial is incorrect. Instead of Hemant P. Purohit it should have been Hemant J. Purohit.

The online version of the original article can be found at http://dx.doi. org/10.1007/s10142-016-0506-z.

Manohar G. Muddeshwar

mmuddeshwar2016@gmail.com

$\triangle$ Shrikant P. Pawar

shrikantpawar@nccs.res.in

1 Department of Biochemistry, Government Medical College,

Nagpur 440009, Maharashtra, India

2 Microbial Culture Collection, National Centre for Cell Science, Pune 411007, Maharashtra, India

3 Environmental Genomics Division, National Environmental Engineering Research Institute, CSIR Nehru Marg, Nagpur 440020, India 